\title{
The implementation of NEMS GFS Aerosol Component (NGAC) Version 2.0 for global multispecies forecasting at NOAA/NCEP - Part 1: Model descriptions
}

\author{
Jun Wang ${ }^{1}$, Partha S. Bhattacharjee ${ }^{2}$, Vijay Tallapragada ${ }^{1}$, Cheng-Hsuan $\mathrm{Lu}^{3}$, Shobha Kondragunta ${ }^{4}$, Arlindo da \\ Silva $^{5}$, Xiaoyang Zhang ${ }^{6}$, Sheng-Po Chen ${ }^{3}$, Shih-Wei Wei ${ }^{3}$, Anton S. Darmenov ${ }^{5}$, Jeff McQueen ${ }^{1}$, Pius Lee ${ }^{7}$, \\ Prabhat Koner ${ }^{8}$, and Andy Harris ${ }^{8}$ \\ ${ }^{1}$ NOAA/NWS National Centers for Environment Prediction, College Park, MD 20740, USA \\ ${ }^{2}$ I. M. Systems Group, INC. at NOAA/NWS National Centers for Environment Prediction, College Park, MD 20740, USA \\ ${ }^{3}$ University at Albany, State University of New York, Albany, NY 12222, USA \\ ${ }^{4}$ NOAA/NESDIS Satellite Applications and Research Center, College Park, MD 20740, USA \\ ${ }^{5}$ NASA Goddard Space Flight Center, Greenbelt, MD 20771, USA \\ ${ }^{6}$ South Dakota State University, Brookings, SD 57007, USA \\ ${ }^{7}$ NOAA/OAR Air Resource Laboratory, College Park, MD 20740, USA \\ ${ }^{8}$ University of Maryland, Earth System Science Interdisciplinary Center, College Park, MD 20740, USA
}

Correspondence: Jun Wang (jun.wang@ noaa.gov)

Received: 10 December 2017 - Discussion started: 22 December 2017

Revised: 27 April 2018 - Accepted: 2 May 2018 - Published: 19 June 2018

\begin{abstract}
The NEMS GFS Aerosol Component Version 2.0 (NGACv2) for global multispecies aerosol forecast has been developed at the National Centers of Environment Prediction (NCEP) in collaboration with the NESDIS Center for Satellite Applications and Research (STAR), the NASA Goddard Space Flight Center (GSFC), and the University at Albany, State University of New York (SUNYA). This paper describes the continuous development of the NGAC system at NCEP after the initial global dust-only forecast implementation (NGAC version 1.0, NGACv1). With NGACv2, additional sea salt, sulfate, organic carbon, and black carbon aerosol species were included. The smoke emissions are from the NESDIS STAR's Global Biomass Burning Product (GBBEPx), blended from the global biomass burning emission product from a constellation of geostationary satellites (GBBEP-Geo) and GSFC's Quick Fire Emission Data Version 2 from a polar-orbiting sensor (QFED2). This implementation advanced the global aerosol forecast capability and made a step forward toward developing a global aerosol data assimilation system. The aerosol products from this system have been used by many applications such as for regional air quality model lateral boundary conditions, satellite sea surface temperature (SST) physical retrievals, and the global
\end{abstract}

solar insolation estimation. Positive impacts have been seen in these applications.

\section{Introduction}

Aerosols affect the atmospheric energy budget by scattering and absorbing solar and thermal radiation and by interacting with clouds. The impact of aerosols on the radiation interaction processes varies with different aerosol species. It is known that sulfate aerosols predominantly reflect sunlight and cool the atmosphere, while black carbon aerosols absorb radiation and warm the atmosphere (Haywood and Boucher, 2001). Organic carbon aerosols also warm the atmosphere depending on the brightness of the underlying ground. Dust impacts radiation to varying degrees depending on the composition of the minerals in the dust grains and whether they are coated with black or brown carbon (Sokolik and Toon, 1999). Sea salt particles scatter the incoming solar radiation and absorb the outgoing terrestrial radiation, with short- and long-wave radiation approximately the same order of magnitude but with the opposite sign (Lundgren et al., 2013). 
In addition to the effect on the atmospheric energy budget, the composition and size distribution of aerosols impact their effectiveness as cloud condensation nuclei $(\mathrm{CCN})$ and result in variations of the distribution of CCN (Mircea et al., 2002). The change in the cloud properties further impacts cloud albedo, cloud lifetime, precipitation, and vertical atmospheric heating profile, etc. (Twomey, 1977; Albrecht, 1989; Lohmann and Feichter, 2005; Rosenfeld, 2006; Stevens and Feingold, 2009). To represent the diverse aerosol properties and estimate their effects on physical radiation and cloud processes, typical aerosol size distributions are adopted. The effect of the physical processes involving aerosols is not limited to climate studies but also affects other earth science systems. Polluted air with an increased amount of aerosols tends to generate bright clouds reducing precipitation efficiently, which then leads to a weak regional hydrological cycle that affects the quality of fresh water over the tropics and the subtropics, especially in the Asian region, which has large tropical and subtropical aerosol emission sources (Ramanathan et al., 2001). Minerals such as nitrogen, phosphorus, and iron that are deposited on land and oceans due to aerosol landing may stimulate productivity in some land ecosystems (e.g., tropical forecast) and marine ecosystems, enhancing $\mathrm{CO}_{2}$ intake and the biogeochemical cycles (Jickells et al., 2005; Mahowald, 2011).

Aerosol impact on weather prediction has been investigated extensively in recent years. Many studies show that aerosols may have a significant impact on severe weather events. Rosenfeld et al. (2012) indicated that microphysical and thermodynamic effects from aerosols have a significant impact on tropical cyclone development. Wang (2014) showed that anthropogenic aerosols from Asian pollution increased the precipitation and poleward heat transport, thereby intensifying the Pacific storm track. Saide et al. (2015) analyzed historical tornado outbreak data in central America and concluded that an increase in aerosols in this region can induce tornado outbreaks when atmospheric conditions are favorable for severe thunderstorm development. Fan et al. (2015) also showed that anthropogenic aerosols contributed to catastrophic floods in southwest China in 2013. These studies illustrate the importance of including a more realistic treatment of aerosol-cloud interactions in numerical weather prediction (NWP) models.

Many major NWP operational centers around the world have started to investigate the impact of aerosol on mediumrange global weather forecasting. Tompkins et al. (2005) showed that an updated dust climatology leads to a northward shift of the African Easterly Jet (AEJ) in the European Centre for Medium-Range Weather Forecasts (ECMWF) NWP model, which agrees with the observations. Their study confirmed that a better representation of the seasonal distribution of aerosol (especially dust) improves the model mean state and local surface weather forecast skill. Reale et al. (2011) studied the impact of aerosol on global weather forecast skill using NASA's Goddard Earth Observing System ver- sion 5 (GEOS-5) and confirmed that forecasts with interactive aerosol radiation effects predicted a more realistic thermal structure and AEJ location in the African monsoon region. They suggested designing an event-focused system to activate aerosol radiation interaction in a global forecast model when there is a strong aerosol event. Grell and Baklanov (2011) suggested that a fully coupled chemical and weather forecast model should be used for weather forecasts and air quality predictions due to the positive improvement observed in temperature and wind forecasts during wild fire events. Therefore, in order to achieve better forecast performance, comprehensive representations of aerosol direct and indirect effects and aerosol-aware physics schemes are required in high-resolution weather forecast models. Mulcahy et al. (2014) investigated aerosol complexity in the global NWP configuration of the Met Office Unified Model (MetUM). They concluded that aerosol species treated as prognostic variables help to predict aerosol events, and when the direct and indirect aerosol effects are represented in the model the radiation bias is reduced and the regional temperature and height forecast is improved for the aerosol events. Zhang et al. (2016) investigated the changes in solar radiation forcing from a smoke event and the corresponding changes in surface cooling and model bias. However, they found that the inclusion of realistic smoke aerosol fields in the forecast model itself is not sufficient to get significant improvement in surface temperature forecasts considering the current range for model temperature uncertainty.

A unified modeling framework for both weather forecast and climate prediction is under development at the National Centers for Environmental Prediction (NCEP). Specifically, NCEP has been developing NOAA Environmental Modeling System (NEMS) as its next-generation operational system (Black et al., 2007, 2009) and has collaborated with the NASA/Goddard Space Flight Center (GSFC) to develop the NEMS GFS Aerosol Component (NGAC) for predicting the distribution of atmospheric aerosols (Lu et al., 2010). Implemented in 2012, NGAC version 1 provided the first operational global dust aerosol forecasting capability at NCEP (Lu et al., 2016). It used an in-line aerosol module based on the Goddard Chemistry Aerosol Radiation and Transport (GOCART) model within GEOS-5. The system was built upon the Earth System Modeling Framework (ESMF), which provided the techniques to implement exchangeable and reusable earth science system components. The atmosphere model was equivalent to the 2010 operational GFS but running at a lower resolution (T126, approximately $100 \mathrm{~km}$ ). The model provided a 5-day dust-only forecast globally at a $1^{\circ} \times 1^{\circ}$ resolution once per day at 00:00 coordinated universal time (UTC).

Based on NGAC version 1, NCEP implemented a multispecies aerosol forecast capability through continuous collaboration among NCEP, NASA/GSFC, the NESDIS Center for Satellite Applications and Research (STAR), and the University at Albany, State University of New York (UAl- 
bany). In Sect. 2, we describe the NGACv2 model configuration. In Sect. 3, we present the operational implementation of NGACv2. In Sect. 4, we present some results of NGACv2 forecasts. In Sect. 5, we demonstrate three examples of NGACv2 downstream applications. Section 6 provides concluding remarks. Detailed NGACv2 verification will be presented in a companion paper (Bhattacharjee et al., 2018).

\section{Model descriptions}

NGAC is an interactive atmospheric aerosol forecast system with the NEMS global spectral model (NEMS GSM) as the atmosphere model and GOCART as the aerosol model. The system was built upon the ESMF infrastructure to streamline the subcomponents in the earth system. NEMS GSM has been developed at NCEP to implement the standalone global forecast system (GFS) in the NEMS framework since 2006 (Black et al., 2007, 2009). NGAC shares the same global forecast system with NEMS GSM. Detailed information on the NEMS GSM can be found in NGACv1 (Lu et al., 2016). The major model updates from NGACv1 to NGACv2 are listed below.

\subsection{Updates in NEMS GSM}

The physics package in NEMS GSM has been updated to the operational GFS physics package for each GFS implementation until NEMS GSM was implemented into operation in 2017. There have been several important physics updates in NEMS GSM since NGACv1 was implemented in 2012. During NGACv2 development, the GFS physics package was implemented into operations in January 2015 with slightly improved performance, and this version of the physics package was implemented into NEMS GSM in October 2015. NGACv2 uses the same physics package as the 2015 version of the operational GFS. Major GFS physics updates since 2012 are listed below.

First, the radiation package Rapid Radiative Transfer Model (RRTM) was upgraded to the Monte Carlo Independent Column Approximation (McICA) radiation package (Pincus et al., 2003). The new radiation package can address sub-grid cloud variability; in particular, it can be applied to the situation with vertically overlapping fractional clouds and when the cloud condensates form inhomogeneously. The planetary boundary layer (PBL) scheme is updated to the hybrid eddy-diffusivity mass-flux (EDMF) scheme (Han et al., 2016).

Besides the updates in the radiation package and PBL scheme, changes are also made in the land surface scheme. The prescribed soil moisture climatology used in the soil moisture nudging scheme is upgraded from NCEP Climate Prediction Center (CPC)'s bucket soil moisture climatology to the climatology derived from the NCEP Climate Forecast
System (CFS) and Global Land Data Assimilation (GLDAS). To enhance the weak land-atmosphere coupling strength in the GFS, the ratio of thermal-to-momentum roughness is modified as a function of vegetation type. A look-up table based on the vegetation type replaced the $1.0^{\circ}$ momentum roughness length climatology to better describe the roughness length. As in NGACv1 (Lu et al., 2016), the NGACv2 uses the relaxed Arakawa-Schubert scheme with enhanced tracer treatment (the RAS scheme; Moorthi and Suarez, $1992,1999)$ which provides the convective mass fluxes at each model layer in the cloud for vertical aerosol transport. The NEMS GSM uses the simplified Arakawa-Schubert scheme (the revised SAS scheme; Han and Pan, 2011) where these convective mass fluxes are currently not available.

\subsection{Aerosol model}

In 2012, NCEP implemented NASA/GSFC's GOCART aerosol module (Colarco et al., 2010) into NGACv2 and NCEP operations. The GOCART module in NGACv1 can simulate atmospheric aerosols (including sulfate, black carbon (BC), organic carbon (OC), dust, and sea salt), and sulfur gases (Chin et al., 2000a, b, 2002, 2003, 2004, 2007, 2009; Ginoux et al., 2001, 2004; Bian et al., 2010; Colarco et al., 2010; Kim et al., 2013), but only the dust module is turned on in NGACv1. In NGACv2 the GOCART module is updated and the suite of aerosol components is turned on to predict a wider range of aerosols. Figure 1 shows the summary of the in-line GOCART aerosol module that is used in GOES-5 and NGACv2. Details of aerosol loss processes for all components including dry deposition, wet removal, and convective scavenging processes are specified in Chin et al. (2002). In NGACv2, a computational error on dust aerosol optical depth (AOD) calculation is fixed, and the removal process has been tuned to improve model performance. Black carbon and organic carbon aerosols are tracked separately in GOCART. The organic carbon is presented as particulate organic matter. The chemical processing of carbonaceous aerosols as a conversion from a hydrophobic to hydrophilic mode follows Cooke et al. (1999) and Chin et al. (2002) with an $e$-folding timescale of 2.5 days (Maria et al., 2004). Following Colarco (2014), five size bins of sea salt aerosol particles with a dry radius range of $0.03-10 \mathrm{~mm}$ are considered for an indirect production mechanism from bursting bubbles (Monahan et al., 1986), as modified by Gong (2003). Four sulfate tracers, i.e., dimethyl sulfide (DMS), $\mathrm{SO}_{2}, \mathrm{SO}_{4}$, and methane sulfonic acid (MSA) are tracked. Sulfate chemistry includes the DMS oxidation by $\mathrm{OH}$ during the day and by $\mathrm{NO}_{3}$ at night to form $\mathrm{SO}_{2}$ and $\mathrm{SO}_{2}$ oxidation by $\mathrm{OH}$ in the gas phase and by $\mathrm{H}_{2} \mathrm{O}_{2}$ in the aqueous phase to form sulfate, as described in Chin et al. (2002). The aerosol optical thickness (AOT) is computed from the complex refractive indices, size distributions, and the hygroscopic properties of aerosols following Chin et al. (2002). 


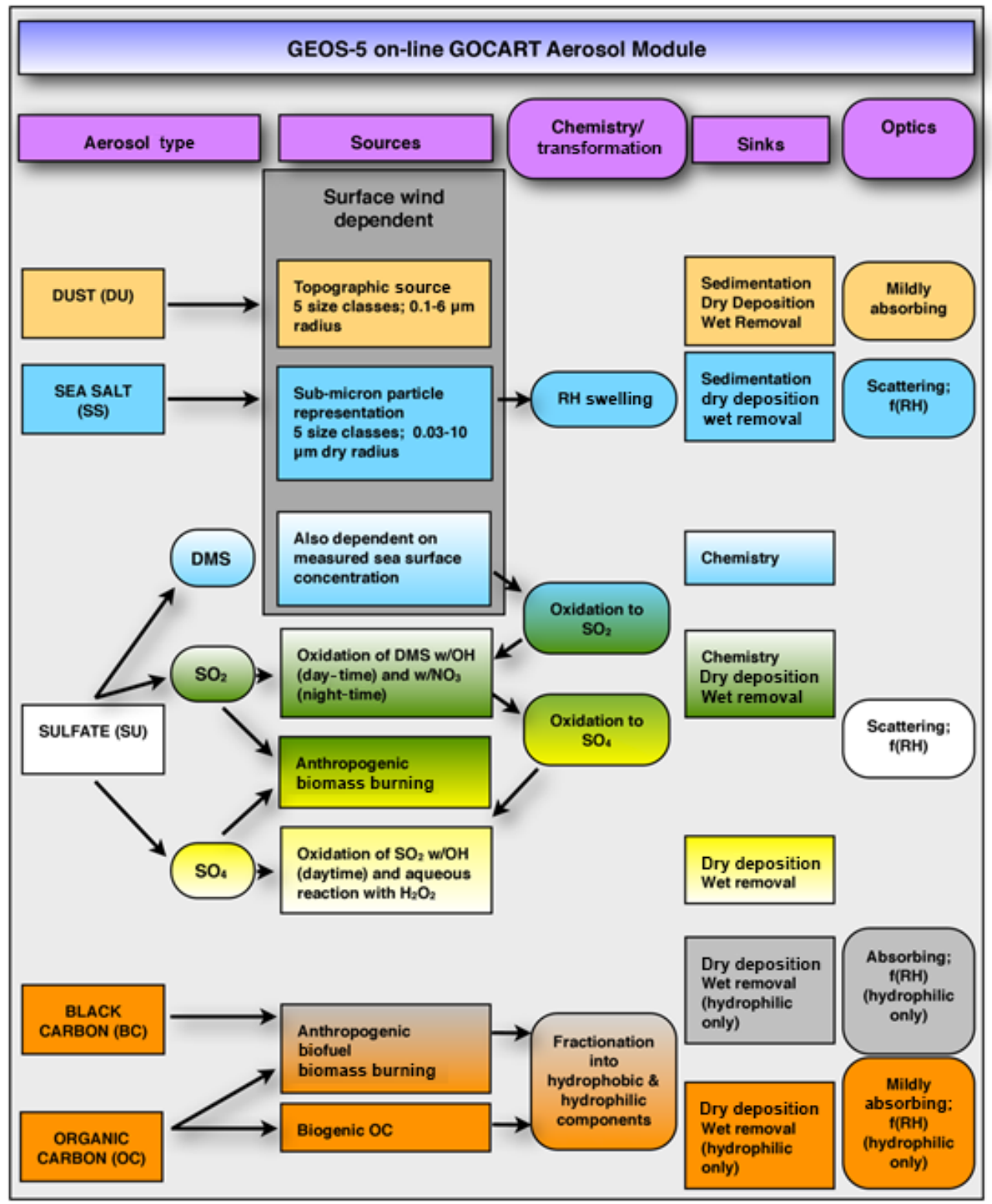

Figure 1. Summary of aerosol modules in GEOS5 (Colarco et al., 2010). This aerosol module is adopted NGACv2. (Provided by Peter Colarco, NASA/GSFC, 2014).

\subsection{Emissions}

With the exception of biomass burning emissions, NGACv2 adopts GEOS-5 GOCART aerosol emissions. Emissions of carbonaceous aerosols and $\mathrm{SO}_{2}$ from biomass burning are obtained from Global Biomass Burning Emission Productextended (GBBEPx) described in Zhang et al. (2014). GBBEPx emissions are blended from NESDIS's Global Biomass Burning Emission Product from a constellation of geostationary satellites (GBBEP; Zhang et al., 2012) and GMAO's Quick Fire Emissions Data Version 2 from polarorbiting satellites (QFED2; Darmenov and da Silva, 2015). GBBEPx provides global emissions for $\mathrm{CO}_{2}, \mathrm{CO}, \mathrm{OC}, \mathrm{BC}$,
$\mathrm{PM}_{2.5}$, and $\mathrm{SO} 2$ daily. The operational implementation of GBBEPx product at NESDIS enables NCEP to upgrade NGAC from dust-only to multispecies aerosol forecasts (including dust, sea salt, sulfate, and carbonaceous aerosols).

Table 1 summarizes the emissions for different aerosol types used by the GOCART aerosol module in NGACv2. Emissions datasets are re-gridded to the native model grid (i.e., T126 Gaussian grid, about $100 \mathrm{~km}$ horizontal resolution). The emission sources/algorithms used for each species are as follows:

- For sulfate aerosols, primary emissions of DMS, $\mathrm{SO}_{2}$, and $\mathrm{SO}_{4}$ are considered. Daily biomass burning emis- 
Table 1. Aerosol and precursor emissions in NGACv2.

\begin{tabular}{lll}
\hline Aerosol type & Sources & Temporal resolution \\
\hline Dust & Wind-driven emissions with Ginoux et al. (2001) & Model \\
Sea salt & Wind-driven emissions & \\
Biogenic terpene & Guenther et al. (1995) & Model \\
Dimethyl sulfide (DMS) & Lana et al. (2011) & Monthly mean climatology \\
& GBBEPx (Zhang et al., 2014) & Monthly mean climatology \\
\hline Biomass burning $\left(\mathrm{SO}_{2}, \mathrm{OC}, \mathrm{BC}\right)$ & EDGAR V4.1 (Janssens-Maenhout, 2010) & Monthly varying \\
\hline Anthropogenic $\mathrm{SO}_{2}$ & AeroCom Phase II (HCA0 v1, Diehl et al., 2012) & Annually varying \\
Anthropogenic $\mathrm{SO}_{4}, \mathrm{POM}_{\text {and }}$ BC & EDGAR V4.1 (Janssens-Maenhout, 2010) & Annually varying \\
International ships $\mathrm{SO}_{2}$ & AeroCom Phase II (HCA0 v1; Diehl et al., 2012) & Annually varying \\
International ships $\mathrm{SO}_{4}, \mathrm{POM}$, and BC & AeroCom Phase II (HCA0 v1; Diehl et al., 2012) & Monthly varying \\
Aircraft $\mathrm{SO}_{2}$ & & \\
\hline
\end{tabular}

sions are taken from NESDIS GBBEPx dataset described above. Anthropogenic emissions of $\mathrm{SO}_{2}$ are taken from the Emissions Database for Global Atmospheric Research (EDGAR), version 4.1 (JanssensMaenhout, 2010). For anthropogenic emissions of primary sulfate, the AeroCom Phase II dataset (HCA0 v1, Diehl et al., 2012) is used. $\mathrm{SO}_{2}$ emissions from oceangoing ships are taken from EDGAR v4.1, and ship $\mathrm{SO}_{4}$ emissions, taken from AeroCom Phase II (HCA0 v1), are derived from gridded emissions dataset of Eyring et al. (2005) using the EDGAR v4.1 $\mathrm{SO}_{2}$ ship emissions. Aircraft emissions of $\mathrm{SO}_{2}$ are derived from the AeroCom Phase II (HCA0 v1), which in turn is based on NASA's Atmospheric Effects of Aviation Program (AEAP) inventory. DMS emissions from marine algae are calculated from DMS concentrations and water-toair transfer velocity (piston velocity). Monthly varying DMS concentrations are taken from Lana et al. (2011). Piston velocity is computed from $2 \mathrm{~m}$ temperature and $10 \mathrm{~m}$ wind following the empirical formula from Liss and Merlivat (1986).

- The sources for carbonaceous aerosols arise from anthropogenic and natural sources, including biomass burning, fossil fuel, biofuel, and (in the case of OC) from the oxidation of biogenic emissions. Biomass burning sources are taken from daily GBBEPx dataset described above. For anthropogenic emissions, the AeroCom Phase II dataset (HCA0 v1) is used. This dataset is based on a gridded inventory from Bond et al. (2004) and yearly global emission trends compiled from Streets et al. (2008, 2009). Ship emissions are determined in the same way as for $\mathrm{SO}_{4}$ (AeroCom Phase II, HCA0 v1). Emissions of terpene from vegetation are oxidized to produce OC aerosols. Biogenic emissions are treated following Chin et al. (2002) using a monthly varying Global Emissions Inventories Activity (GEIA) inventory (Guenther et al., 1995).
- For natural aerosols, the emissions are largely driven by variability in model dynamics (specifically, the surface wind). Dust emissions use a map of potential dust source locations based on topographic depressions (Ginoux et al., 2001). The uplifting of dust aerosols depend on the wind speed formulation of Marticorena and Bergametti (1995). The parameterization of sea salt emissions follows the formulation of Gong (2003).

Time frequency of emissions differs between different sources. Both dust and sea salt have wind-speed-dependent emissions, updated every time step. Biomass burning emissions from GBBEPx are updated daily. For other emissions, annually and monthly varying emissions are temporally interpolated using linear interpolation. For instance, anthropogenic carbonaceous and primary sulfate aerosols emissions from AeroCom Phase II, HCA0 v1 cover the period 1976-2006. For retrospective NGACv2 experiments, emissions are linearly interpolated between the available years. For real-time NGACv2 forecasts, the latest available emissions (2006 emissions) are used.

\section{NGAC Version 2 operational implementation}

A phased implementation approach is used for the NGAC implementation at NCEP. The first implementation was for dust-only forecasts. The current NGACv2 implementation documented here enabled the capability of multispecies aerosol forecast including carbonaceous aerosols, sea salt and sulfate aerosols. An aerosols data analysis system capability is under development targeted for the third phase of the NGAC upgrade. The phased implementation also includes both science and software upgrades in the global forecast system.

Effective on 7 March 2017, starting with the 00:00 UTC cycle, NCEP began to run and disseminate data from the NGACv2 system operationally. NGACv2 runs at T126 L64 resolution and provides 5-day multispecies aerosols fore- 
casts, twice per day for the 00:00 and 12:00 UTC cycles. The NGACv2 initial conditions are taken from the $12 \mathrm{~h} \mathrm{NGACv2}$ forecast from the previous cycle, while meteorological initial conditions are from the downscaled high-resolution Global Data Assimilation System (GDAS) analysis.

As specified in Sect. 2, the NGACv2 has an atmosphere model updated to the latest GFS, implemented in May 2016. However, NGACv2 uses the same configuration as operational GFS except a different convection scheme. NGACv2 provides products in addition to those from NGACv1 dustrelated products. First, total AOD and AOD from each species are produced to support global and regional multimodel ensemble aerosol forecasts. Second, single scattering albedo and asymmetric factor for total aerosols at $340 \mathrm{~nm}$ are produced to support a UV index forecast. Third, threedimensional mixing ratios for each aerosol species at model levels are produced to support NCEP's operational regional Community Multiscale Air Quality model (CMAQ) and satellite sea surface temperature (SST) retrieval. A complete list of the new output fields is in Appendix A.

\section{NGAC Version 2 results}

In this section, the results for the emissions and budgets from operational NGACv2 forecasts and a case study are presented. A detailed NGACv2 performance review is presented in a separate companion paper (Bhattacharjee et al., 2018).

\subsection{Budgets}

A retrospective NGACv2 run was conducted for the June 2015 to February 2017 period. Figure 2 shows the global annual emission, burden, and lifetime (or atmospheric residence time) calculated from NGACv2, relative to other similar global aerosol models, including GEOS-4 (Colarco et al., 2010), the models participating in the AeroCom model intercomparison studies (Textor et al., 2006) and NGACv1 (for the case of dust).

Large differences are found in emissions, burdens, and lifetimes within the AeroCom models, which are primarily related to the differences in the emission parameterizations, the particle sizes, the meteorological fields and model configuration used in the individual models (Textor et al., 2006). The simulated total emissions, annual burden, and lifetime of all the aerosol species in NGACv2 are within the range of the AeroCom models. The dust emissions, annual burden and lifetime are shown in the column a in upper three plots in Fig. 2. The first bar is the field from NGACv2 and the fourth bar is same field from NGACv1. Compared to NGACv1, NGACv2 has larger dust emissions due to GFS physics updates (2379 vs. $1980 \mathrm{Tg} \mathrm{yr}^{-1}$ ). In NGACv2, the dust lifetime is longer than NGACv1 (7.45 vs. 4.3 days) and the annual burden is about 50\% more than NGACv1 (30.6 vs. 21.9 Tg), but closer to in-line GOCART in GEOS-4 (30.7 vs. $31.6 \mathrm{Tg}$ ). These results suggest that dust in NGACv2 is closer to GEOS-4 dust when compared to NGACv1. Sea salt emission is lower than in GEOS-4 (8660 vs. $9729 \mathrm{Tg} \mathrm{yr}^{-1}$ ), and its burden lifetime is slightly less than that in GEOS-4. In NGACv2, the emissions of black carbon and organic carbon are larger than in GEOS-4 due to the different biomass burning emissions; however, their burden and lifetime are smaller than the GEOS-4 because of the relatively large removal process. Sulfate emission is slightly smaller than that in GEOS-4 (55.47 vs. $58.73 \mathrm{Tg} \mathrm{yr}^{-1}$ ); NGACv2 sulfate also has less burden and lifetime. It is worth noting that the NGAC emissions, budget, and lifetime presented here are in the context of the AeroCom model suite. Evaluation of aerosol budget, emissions, and lifetime using observations is beyond the scope of this study.

\subsection{Case study}

Figure 3 shows the total aerosol optical depth simulated by NGACv2 during a smoke event from Canadian wildfires during 27 June-6 July 2015. A strong trough and jet stream dominated the middle of North America, and the wind transported the smoke plume toward the southeast from Canada to the Dakotas, Nebraska, and several other states and then reached the Great Lakes region. Elevated AOD associated with the smoke plume has been observed by the space-borne Moderate Resolution Imaging Spectroradiometer (MODIS) sensor and Visible Infrared Imaging Radiometer Suite (VIIRS). The spatial pattern is also predicted by International Cooperative for Aerosol Prediction Multi-Model Ensemble (ICAP-MME; Sessions et al., 2015). The AOD simulated by NGACv2 are consistent with ICAP-MME as well as the observations from MODIS and VIIRS imagery. However, NGACv2 fails to capture the large AOD over the south of the Great Lakes that is shown in the satellite retrievals and the ICAP-MME.

ICAP-MME total AOD products are generated from aerosol forecasts from four well-established aerosol models, including NASA/GSFC, ECMWF, Naval Research Laboratory (NRL), and Japan Meteorological Agency (JMA). Nearreal-time satellite-based smoke emissions are used by the four ICAP core models, e.g., QFED2 for NASA/GSFC, Fire Locating and Modeling of Burning Emissions (FLAMBE) by NRL, and Global Fire Assimilation System (GFAS) by ECMWF and JMA. In additional, aerosol data assimilation has been utilized by all these models to constrain the modeled AOD errors and bring modeled AODs closer to the satellite observations. Less satisfactory performance in NGAC v2 with respect to ICAP-MME suggests the need for additional model tuning. However, the performance differences cannot be attributed to NGACv2 model deficiency alone. Lynch et al. (2016) reported that the model tuning process is equally as significant as data assimilation on the model performance. Sessions et al. (2015) reported that ICAP-MME outperforms the participating members, providing valuable aerosol forecast guidance. Therefore, the results that multi-model ensem- 
(a)
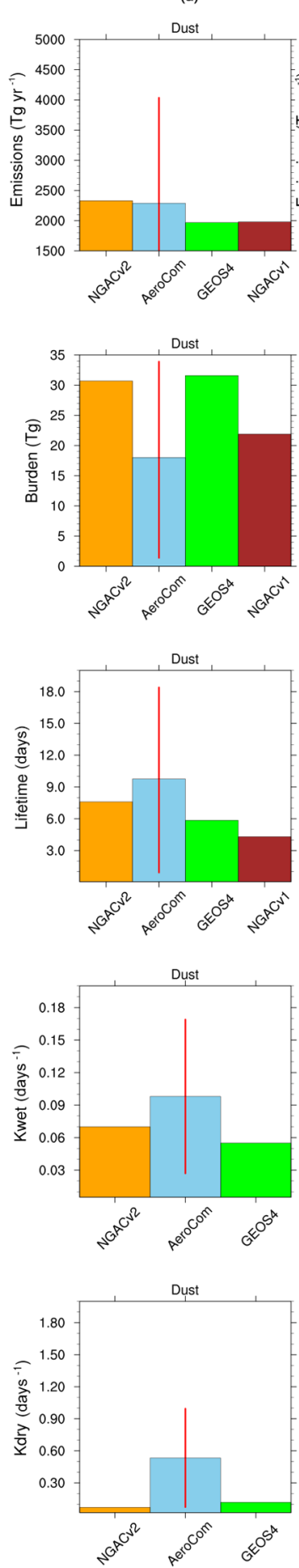

(b)
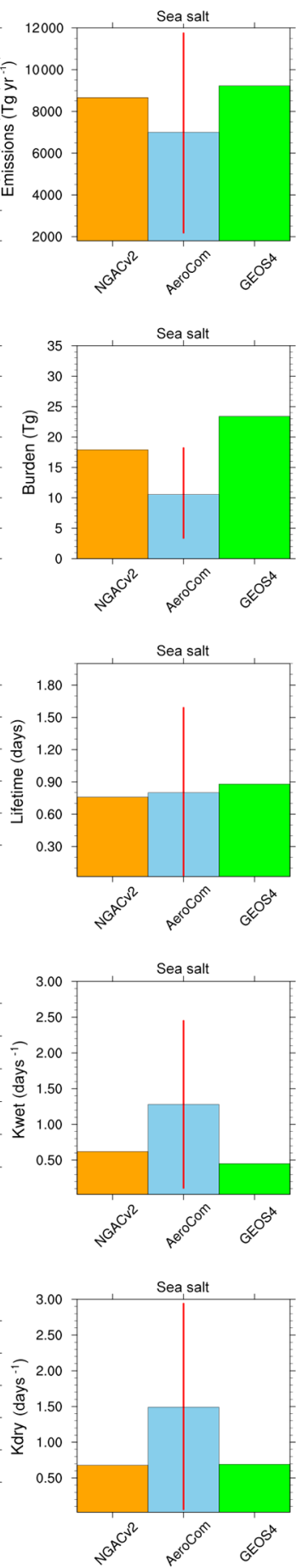

(c)
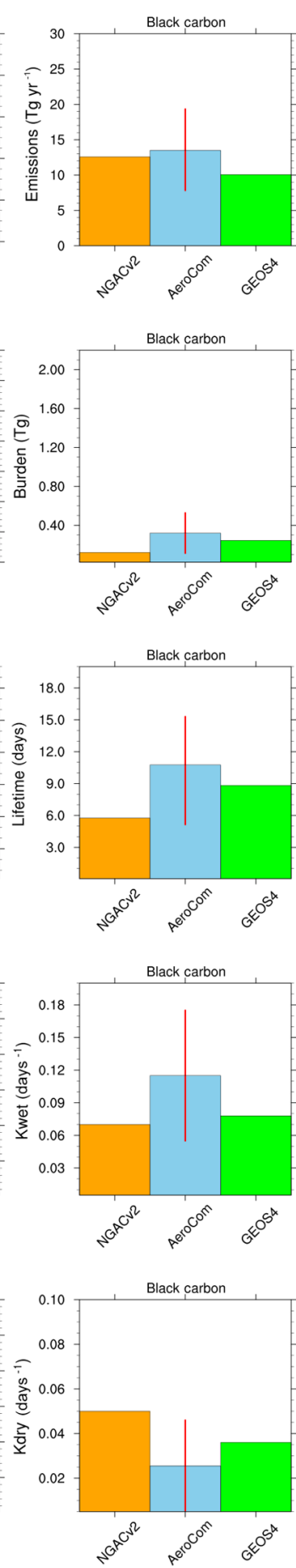

(d)
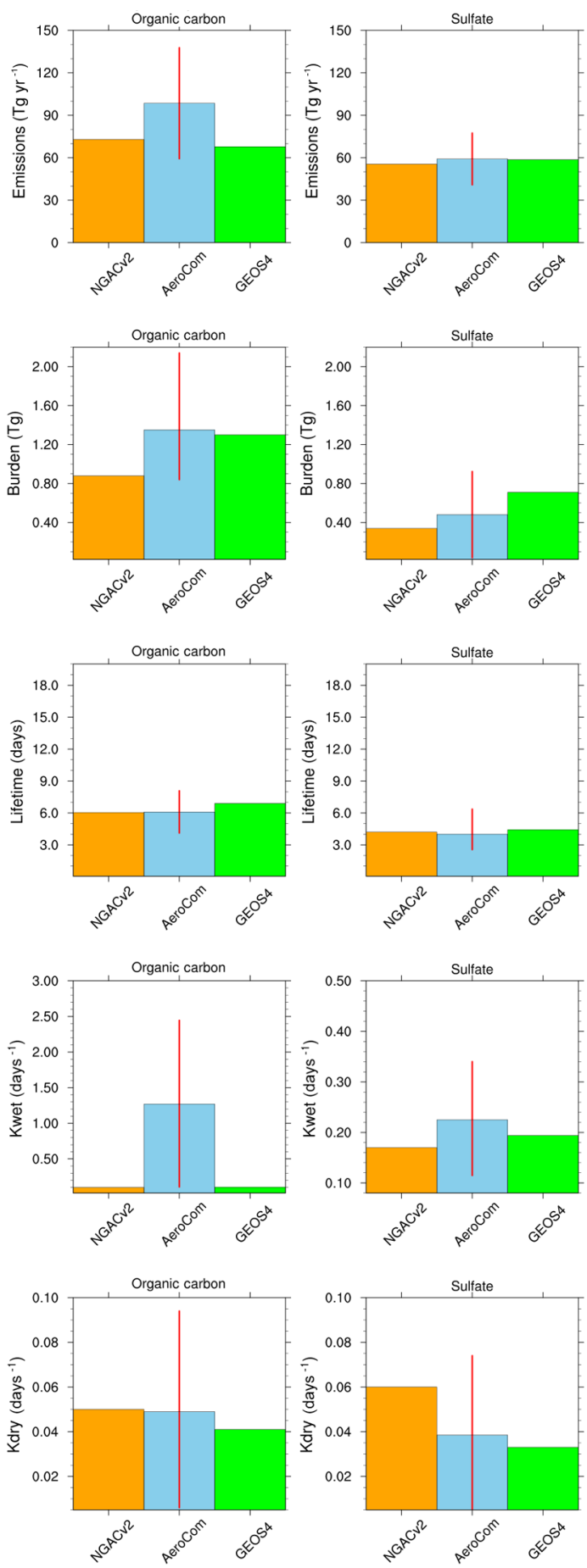

Figure 2. Global annual total aerosol emissions and annual average aerosol burdens, lifetimes, and loss frequencies in NGACv2, AeroCom models, GOES4, and NGACv1 (dust-only). For AeroCom models, the red vertical lines show the maximal and minimal values, and the bar shows the mean value. Column (a) is for dust, column (b) is for sea salt aerosols, column (c) is for black carbon, column (d) is for organic carbon, and column (e) is for sulfate. Sulfate is for sulfur amount only (Colarco et al., 2010).

ble from four well-established models with data assimilation capabilities outperforms a single model without data assimilation are somehow anticipated. 

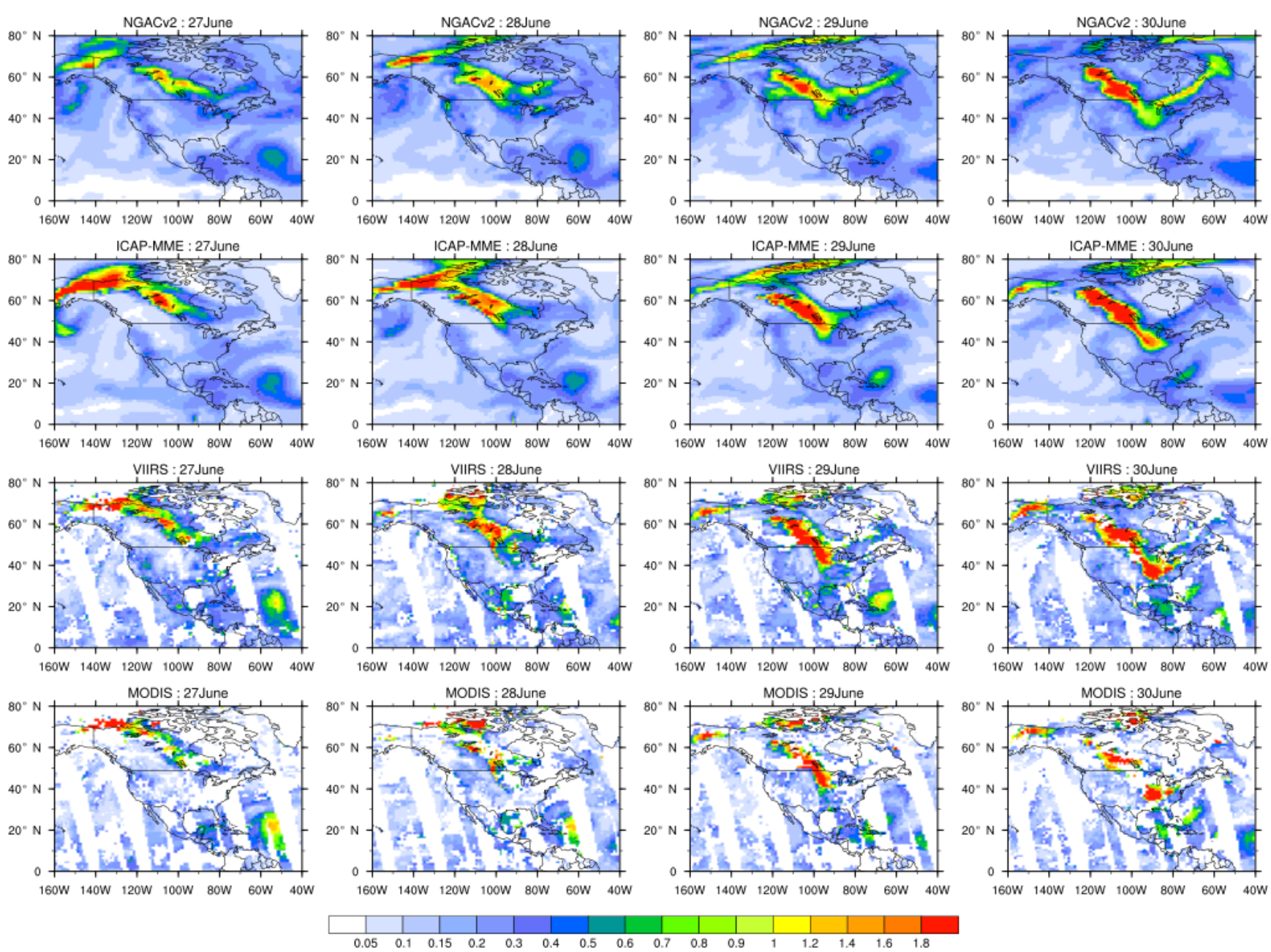

Figure 3. Smoke event of 27 June to 6 July 2015 from NGACv2 and ICAP forecasts and VIIRS and MODIS satellite observations.

\section{NGAC Version 2 application}

The implementation of NGACv2 will provide a full suite of two-dimensional (2-D) and three-dimensional (3-D) aerosol products for various downstream applications. Examples of NGACv2 product applications are given here.

\subsection{Dynamic boundary conditions for regional air quality model}

One direct application of NGAC is to provide dynamic boundary conditions for regional air quality models such as Community Multiscale Air Quality (CMAQ) modeling system. The utilization of NGAC for CMAQ with zeroflux divergence outflow and prescribed concentrations for inflow chemical lateral boundary conditions for the dustassociated aerosol has been operational since February 2016 under the auspices of the National Air Quality Forecasting Capability (NAQFC) (Lee et al., 2017). CMAQ previously used static climatology boundary conditions as lateral boundary conditions, which limited the regional forecast capabil- ity when an aerosol event moved into the regional domain from the CMAQ boundary. Figure 4 shows an event on 1012 June 2015 when smoke from Canada was moving into the United States. Column a is the $\mathrm{PM}_{2.5}$ forecast on 10,11 , and 12 June from the CMAQ run using GEOS-Chem model 2006 monthly average values for all the aerosol species at the lateral boundary. Column $\mathrm{b}$ is the $\mathrm{PM}_{2.5}$ forecast from CMAQ during the same period using NGACv2 multispecies aerosols as the lateral boundary condition. $\mathrm{PM}_{2.5}$ observations in cycled dots are also shown in both panels to compare CMAQ forecast with observations. Column $\mathrm{c}$ is the difference between the two runs. The figure shows that no smoke was predicted over central Canada and the US in the run using the climatology as the lateral boundary condition, while the run using NGAC multispecies aerosols as the boundary condition shows a large amount of smoke passing the USCanadian border and coming across the Great Lakes region. The figure shows that using the NGAC forecast as the CMAQ lateral boundary condition significantly improved the CMAQ forecast. 
(a)

BASE

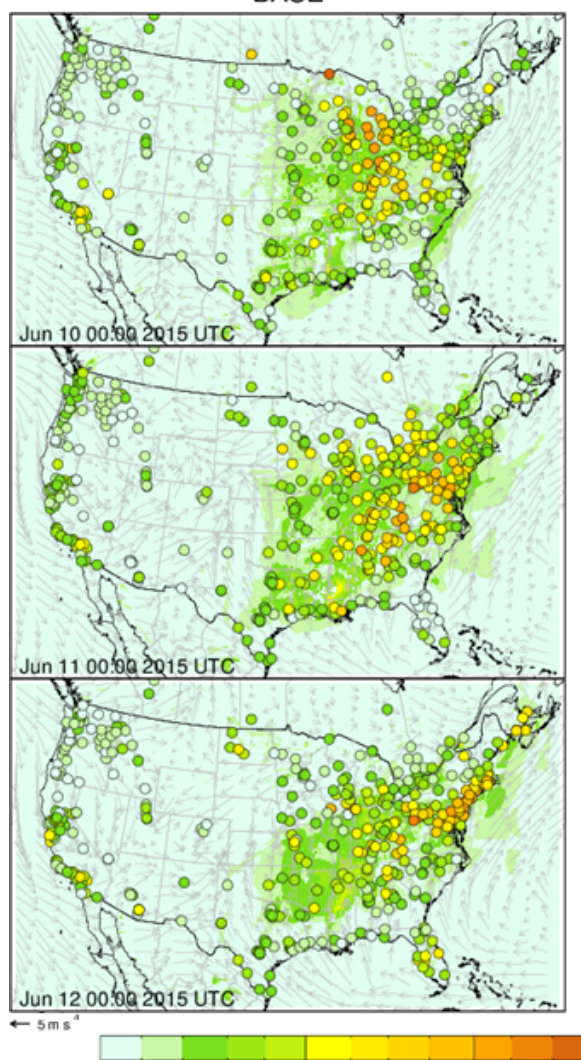

(b)

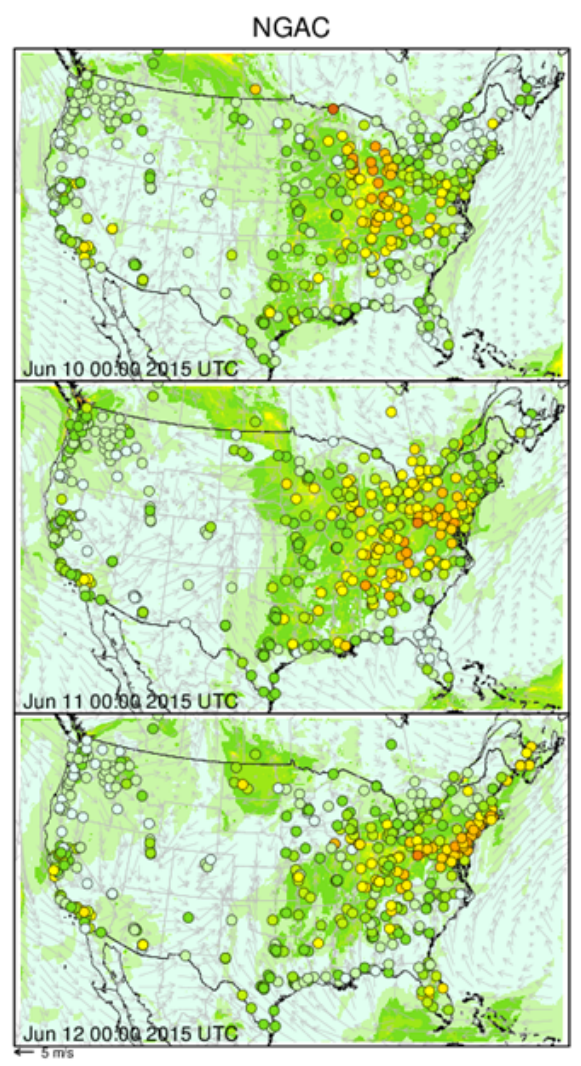

(c)

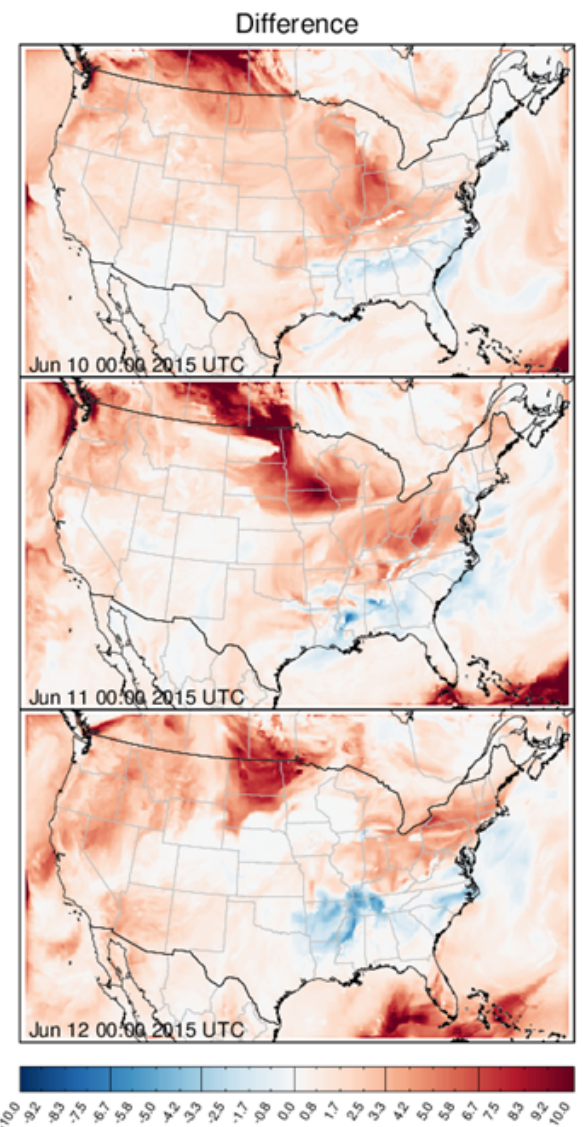

Figure 4. $\mathrm{PM}_{2.5}$ forecasts from regional air quality model CMAQ during the smoke event on 10-12 June 2015. Base: using GEOS-Chem model 2006 monthly average as lateral boundary condition; NGAC: using NGACv2 forecast as lateral boundary condition, observations are the circled colored dots. Differences between the two forecasts are shown in column (c).

Figure 5 shows the surface $\mathrm{PM}_{2.5}$ with frontal passages in the 9-12 June 2015 Canadian fire. Panel (a) is the averaged surface $\mathrm{PM}_{2.5}$ from 95 sites in the central United States from 7 to 15 June. Panel (b) is the averaged surface $\mathrm{PM}_{2.5}$ from 82 sites in the northeast United States during the same time period. The line with circular dots is observations. The black line is the CMAQ forecast with climatology as the lateral boundary condition. The blue line is CMAQ using the operational NGAC dust-only forecast as the lateral boundary condition. The red line is the CMAQ forecast using NGACv2 multispecies aerosol forecasts. It is clear that the run with the NGACv2 forecast is closer to observations than the runs from the other experiments even though the peak of $\mathrm{PM}_{2.5}$ in this run is still lower than the observations.

\subsection{Satellite SST retrieval}

An example presented in Fig. 6 focused on exploring and refining the use of aerosol information in physical deterministic retrievals of sea-surface temperature (SST). This experiment has been conducted for nighttime scenarios using matchup data and cloud-free conditions identified using an experimental filter (EXF; Koner et al., 2016). NGAC 3-D aerosol predictions are used as input to the Community Radiative Transfer Model (CRTM), along with GFS profiles of humidity and temperature. Aerosol column density (ACD) of all aerosols is represented by the single Jacobian value that are calculated in CRTM representing the derivative of radiation transfer equation with respect to a single variable, the ACD is then included in the state vector for the MODIS-Aqua SST retrieval. Additional channels available for MODIS, combined with a three-element reduced state vector, offer the prospect of testing a variant of the truncated total least squares (TTLS, Koner and Harris, 2016) approach. A comparison between results for the two-component [SST, total column water vapor (TCWV)] for the modified total least squares (MTLS, Koner et al., 2015) algorithm and three-component [SST, TCWV, ACD] state vectors is shown in Fig. 6. It can be seen that the RMSE (dashed standard deviation lines) is improved noticeably when ACD is a retrieved parameter. A further consequence of including ACD in the state vector is that algorithm sensitivity is significantly improved. This is demon- 


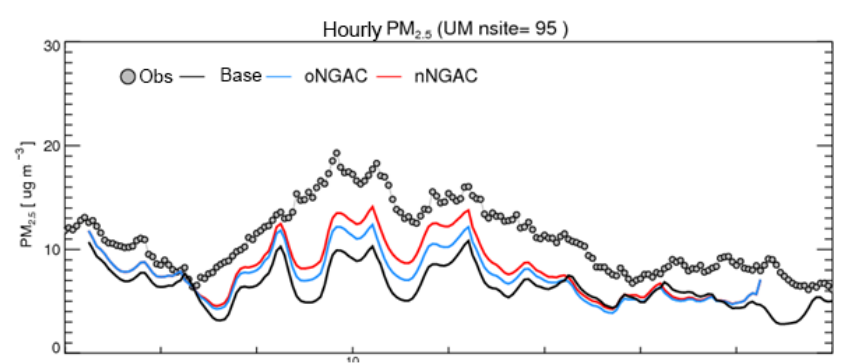

(a)

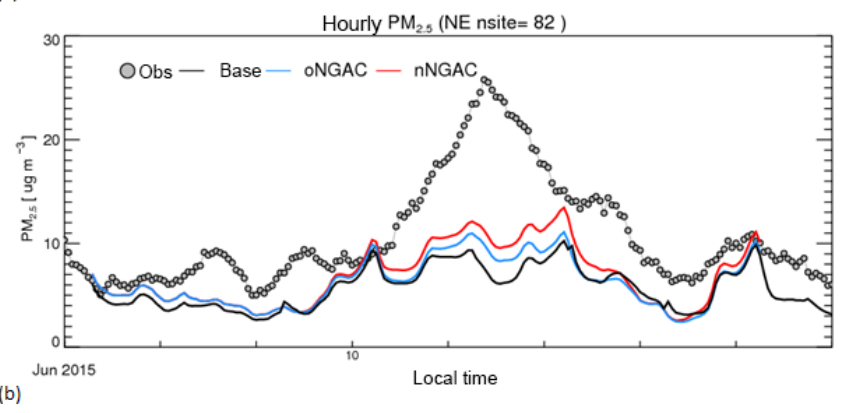

Figure 5. Surface $\mathrm{PM}_{2.5}$ with frontal passages in the 9-12 June 2015 Canadian fire. Panel (a) is the averaged surface $\mathrm{PM}_{2.5}$ from 95 sites in the middle of the United States from 7 to 15 June. Panel (b) is the averaged surface $\mathrm{PM}_{2.5}$ from 82 sites in the northeast of United States. The line with circular dots is observations. The black line is the CMAQ forecast with climatology as a lateral boundary condition. The blue line is the CMAQ using operational NGAC dust-only forecast as a lateral boundary condition. The red line is the CMAQ forecast using an NGACv2 multispecies aerosol forecast.

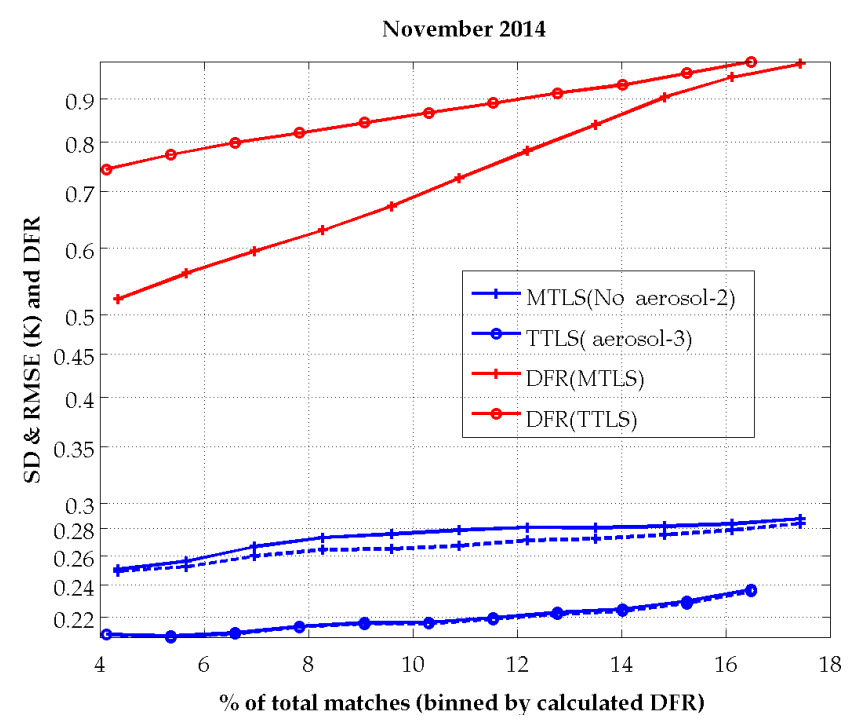

Figure 6. Comparison of retrieval accuracy (blue lines) and algorithm sensitivity (degrees of freedom in retrieval; red lines) of MTLS (plus) without aerosol and truncated total least squares (solid circles) using aerosol optical depth in the state vector for MODISAqua data for January 2015. Evaluation is done against $i$ Quam buoy data.

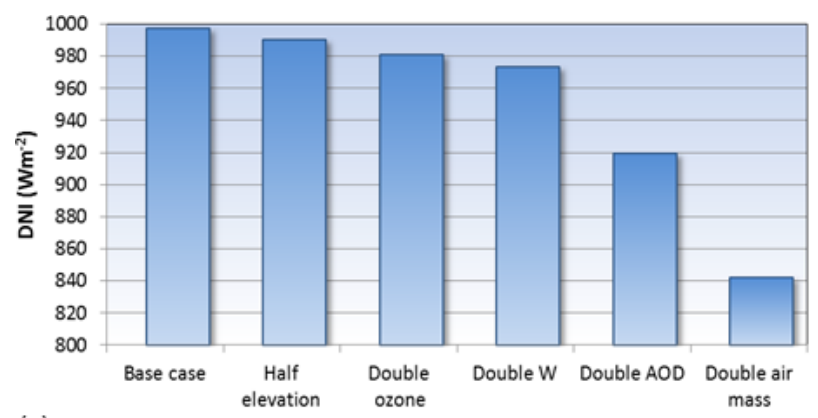

(a)

\section{MBE}

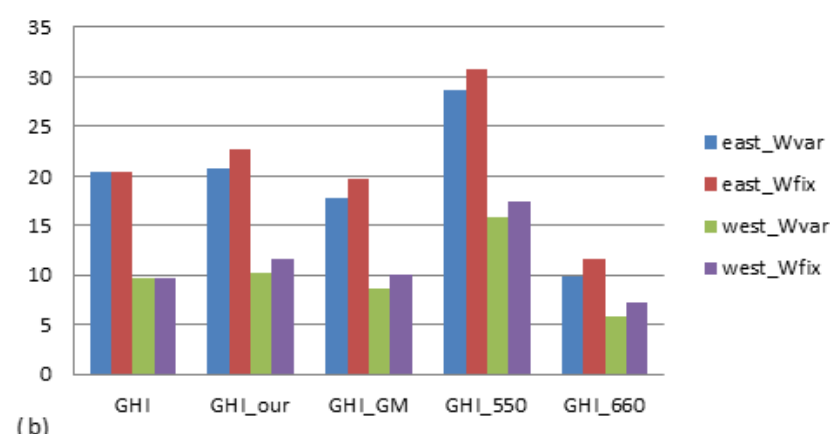

Figure 7. (a) Aerosol impact on DNI from Perez model estimations; (b) NGACv2 AOD impact on Perez model solar energy estimation mean bias error (MSE). East - GOES eastern USA satellite; west - GOES western USA; Wvar - variable water vapor (GFS model); Wfix - monthly averaged water vapor (NASA); our - monthly averaged AOD used in ASRC (NASA); GM - Gueymard AOD; 550 and $660-$ NGACv2 AOD.

strated by the increase in the degree of freedom in retrieval (DFR) values to 0.75 and above. The NGACv2 aerosol products make it possible to design the TTLS scheme; further development is required to improve the SST retrieval using aerosol products in real operation.

\subsection{Insolation on the earth surface estimation}

An estimation of the insolation on the earth surface is another application where the NGACv2 multispecies aerosol forecast can be directly used. The NGACv2 aerosol forecast AOD products were incorporated to the semiempirical GOES satellite global and direct horizontal irradiance estimation model (Perez model) developed at the Atmospheric Sciences Research Center (ASRC) at the State University of New York at Albany (Perez et al., 1990, 2002, 2015). The investigation period consisted of 3 months in the spring of 2016. To compute all sky irradiance, the model needs environmental inputs, such as altitude, and atmospheric condition variables, such as air temperature, water vapor, AOD, and ozone. Model sensitivity tests were conducted to investigate the relative importance of the factors that influence the insolation on the earth surface. Figure 7 a shows the sensitivity of the direct normal irradiance (DNI) (Bird and Hul- 


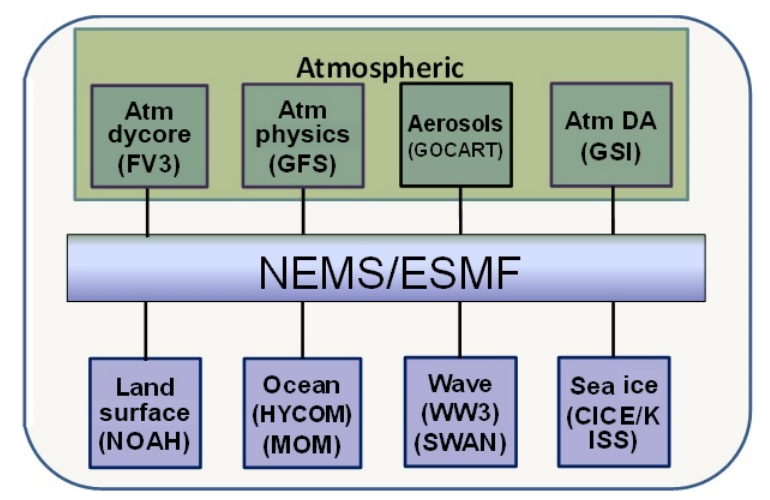

Figure 8. Next Generation of Global Prediction System (NGGPS) implementation plan.

strom, 1981) component of the Perez model to factors such as altitude, ozone, moisture, aerosols, and air mass. It can be seen that compared to double ozone, double moisture, or a decrease in elevation, double AOD has a larger impact on available DNI. Figure $7 \mathrm{~b}$ shows the aerosol impact on the mean bias error (MBE) of global horizontal irradiance (GHI) from the Perez model. The GHI is computed from the Perez model with AOD and water vapor from different sources. Five sets of experiments were conducted to show the GHI MBE. "GHI" is the control experiment with monthly averaged AOD from NASA Earth Observations (NEO) and water vapor from NEO or GFS. Validation is performed on two sets of sites: one set is validated against the GOES eastern US satellite (GOES-13), the other against the GOES western US satellite (GOES-15). "GHI_our” experiment uses the monthly averaged AOD from ASRC. "GHI GM" uses Gueymard AOD (Gueymard, 2008); GHI with NGACv2 AOD at $550 \mathrm{~nm}$ and GHI with NGACv2 AOD at $660 \mathrm{~nm}$ are also shown. It is found that GHI MBE is the smallest for the experiment using NGAC AOD at $660 \mathrm{~nm}$ for the 2016 spring period. The results indicate potential improvement in the operational insolation estimate using NGAC AOD at $660 \mathrm{~nm}$.

\section{Conclusions}

The implementation of NGACv2 provides operational global multispecies aerosol forecasts at NCEP. Total emissions, annual burden, and lifetime from all the aerosol species in NGACv2 are within the range of the AeroCom models and comparable to those in GEOS-4. More extensive evaluation of NGACv2 is presented in the companion paper by Bhattacharjee et al. (2018). Because the results will be used as a baseline for some future development work described below, a general description of the NGACv2 evaluation is shown here. Dust forecast skill is comparable to that in NGACv1 after the bug fix and removal process tuning. The longrange dust transport of Sahara dust is slightly improved. Sea salt performs normally compared to other models. Sul- fate, black carbon, and organic carbon are unrepresentative in North America, the sub-Saharan region, and South America in smoke season. Generally, fire activity shows up in the right location, but the concentration is too low compared to observations. The upgrade from a dust-only system to a multispecies system enables NCEP to produce a full suite of aerosol products to serve a wide range of stakeholders, such as air quality and health professionals, aviation authorities, policy makers, and climate scientists. CMAQ experiments using the NGAC multispecies aerosol forecast as boundary conditions show positive impacts for a smoke event compared to the operational configuration using static boundary conditions. Using NGACv2 AOD $660 \mathrm{~nm}$ improves the mean bias errors in the estimation of surface insolation.

The evaluation of NGACv2 forecast results shows that the initial conditions could have a significant impact on model performance. Currently, NGACv2 is using the forecasted aerosol from the previous cycle and downscaled meteorology fields from the NCEP operational high-resolution data assimilation analysis. Without real-time assimilation the initial aerosol fields may contain errors that propagate to all forecast hours. The aerosol data assimilation using VIIRS in GSI is under development and expected to be implemented in the near future. The future direction for NGAC will be focused on: (1) implementing aerosol data assimilation toward improving aerosol forecasts and (2) improving the representation of aerosol-radiation-cloud interaction in the atmosphere model toward improving weather forecast and climate prediction.

The National Weather Service (NWS) is transitioning their operational GFS to a unified, fully coupled Next Generation Global Prediction System (NGGPS) within NEMS. The new system will take the most recent advances in weather prediction modeling from NOAA and the research community to extend weather forecasting to 30 days and to improve hurricane track and intensity forecast, in addition to improving medium-range weather prediction. This system (Fig. 8) is an earth science system with six components including atmosphere, ocean, land, sea ice, wave, and aerosol. Recently the NOAA Geophysical Fluid Dynamic Laboratory (GFDL)'s Finite Volume Cubed Sphere (FV3) dynamical core was selected as the new NGGPS atmospheric model. The prototype NGGPS system FV3GFS has been developed by coupling FV3 dynamic core with GFS unified physics suite (the same physics suite in NEM GSM) under the NEMS framework. The first FV3GFS release became public on 15 May 2017. NGAC global aerosol forecast capability is now being transitioned to the FV3GFS system; the NGACv2 forecast performance described above will be used as a baseline to evaluate the FV3GFS-based aerosol system. Besides the change in the atmosphere model, the development direction on improving aerosol forecast performance, prognostic capability, adding data assimilation component, and coupling with radiation/clouds remains the same. 
Code and data availability. NCEP Operational Products Suite products are distributed in near real time at the NOAA Operational Model Archive and Distribution System (NOMADS). The website is accessible to public users free of charge. NGACv2 products are available at http://www.nomads.ncep.noaa.gov/pub/data/nccf/com/ ngac/prod (last access: 12 June 2018).

The source code, scripts, parameters, and fixed field files can be obtained at http://www.nco.ncep.noaa.gov/pmb/codes/nwprod/ ngac.v2.3.0/ (last access: 12 June 2018).

Web graphics will remain available at http://www.emc.ncep. noaa.gov/gmb/NGAC/html/realtime.ngac.html (last access: 12 June 2018).

NGAC products are encoded in GRIB2. The NCEP grib2 table is updated to include the definition of new aerosol types. Users should download the latest versions of wgrib2 and the other NCEP GRIB utilities to use the NGAC output products.

A website containing retrospective run results from NGACv2 for the period of June 2015-December 2016 is at http://www.emc.ncep. noaa.gov/gmb/NGAC/NGACv2/ (last access: 12 June 2018). 


\section{Appendix A: New NGAC products}

Output files and the new fields for NGACv2 (Q2FY2017 Implementation)

1. ngac.tCCz.a2dfHHH.grib2, where $\mathrm{HHH}=00,03, \ldots$, 120 and $\mathrm{CC}=00,12$ :

ASYSFK: asymmetry factor at $340 \mathrm{~nm}$ from total aerosols (numeric)

SSALBK: single scattering albedo at $340 \mathrm{~nm}$ from total aerosols (numeric)

AOTK: aerosol optical thickness at $550 \mathrm{~nm}$ from total aerosols (numeric)

AOTK: aerosol optical thickness at $550 \mathrm{~nm}$ from sea salt aerosol (numeric)

AOTK: aerosol optical thickness at $550 \mathrm{~nm}$ from black carbon dry aerosol (numeric)

AOTK: aerosol optical thickness at $550 \mathrm{~nm}$ from particulate organic carbon dry aerosol (numeric)

AOTK: aerosol optical thickness at $550 \mathrm{~nm}$ from sulfate dry aerosol (numeric)

DUST_SCAVENGING_FLUX: dust wet deposition by convective precipitation flux fluxes $\left(\mathrm{kg} \mathrm{m}^{-2} \mathrm{~s}^{-1}\right)$

SEASALT_EMISSION_FLUX: sea salt emission mass flux $\left(\mathrm{kg} \mathrm{m}^{-2} \mathrm{~s}^{-1}\right)$

SEASALT_SEDIMENTATION FLUX: sea salt sedimentation mass flux $\left(\mathrm{kg} \mathrm{m}^{-2} \mathrm{~s}^{-1}\right)$

SEASALT_DRY_DEPOSITION_FLUX: sea salt drydeposition mass flux $\left(\mathrm{kg} \mathrm{m}^{-2} \mathrm{~s}^{-1}\right)$

SEASALT_WET_DEPOSITION_FLUX: sea salt wet deposition by large-scale precipitation mass flux $\left(\mathrm{kg} \mathrm{m}^{-2} \mathrm{~s}^{-1}\right)$

SEASALT_SCAVENGING_FLUX: sea salt wet deposition by convective precipitation mass flux $\left(\mathrm{kg} \mathrm{m}^{-2} \mathrm{~s}^{-1}\right)$

BC_EMISSION_FLUX: black carbon emission mass flux $\left(\mathrm{kg} \mathrm{m}^{-2} \mathrm{~s}^{-1}\right)$

BC_SEDIMENTATION_FLUX: black carbon sedimentation mass flux $\left(\mathrm{kg} \mathrm{m}^{-2} \mathrm{~s}^{-1}\right)$

BC_DRY_DEPOSITION_FLUX: black carbon drydeposition mass flux $\left(\mathrm{kg} \mathrm{m}^{-2} \mathrm{~s}^{-1}\right)$

BC_WET_DEPOSITION_FLUX: black carbon wet deposition by large-scale precipitation mass flux $\left(\mathrm{kg} \mathrm{m}^{-2} \mathrm{~s}^{-1}\right)$
BC_SCAVENGING_FLUX: black carbon wet deposition by convective precipitation mass flux $\left(\mathrm{kg} \mathrm{m}^{-2} \mathrm{~s}^{-1}\right)$

OC_EMISSION_FLUX: particulate organic carbon emission mass flux $\left(\mathrm{kg} \mathrm{m}^{-2} \mathrm{~s}^{-1}\right)$

OC_SEDIMENTATION_FLUX: particulate organic carbon sedimentation mass flux $\left(\mathrm{kg} \mathrm{m}^{-2} \mathrm{~s}^{-1}\right)$

OC_DRY_DEPOSITION_FLUX: particulate organic carbon dry-deposition mass flux $\left(\mathrm{kg} \mathrm{m}^{-2} \mathrm{~s}^{-1}\right)$

OC_WET_DEPOSITION_FLUX: particulate organic carbon wet deposition by large-scale precipitation mass flux $\left(\mathrm{kg} \mathrm{m}^{-2} \mathrm{~s}^{-1}\right)$

OC_SCAVENGING_FLUX: particulate organic carbon wet deposition by convective precipitation mass flux $\left(\mathrm{kg} \mathrm{m}^{-2} \mathrm{~s}^{-1}\right)$

2. ngac.tCCz.a2dfHHH.grib2, where $\mathrm{HHH}=00,03, \ldots$, 120 and $\mathrm{CC}=00,12$ :

Data fields are instantaneous on $1^{\circ} \times 1^{\circ}$ lat-long grid.

SEASALT1: sea salt bin1 (diameter: 0.06-0.2 $\mu \mathrm{m}$ ) mixing ratio $(\mathrm{kg} / \mathrm{kg})$

SEASALT2: sea salt bin2 (diameter: $0.2-1 \mu \mathrm{m}$ ) mixing ratio $(\mathrm{kg} / \mathrm{kg})$

SEASALT3: sea salt bin3 (diameter: $1-3 \mu \mathrm{m}$ ) mixing ratio $(\mathrm{kg} / \mathrm{kg})$

SEASALT4: sea salt bin4 (diameter: $3-10 \mu \mathrm{m})$ mixing ratio $(\mathrm{kg} / \mathrm{kg})$

SEASALT5: sea salt bin5 (diameter: 10-20 $\mu \mathrm{m}$ ) mixing ratio $(\mathrm{kg} / \mathrm{kg})$

BC1: black carbon hydrophobic dry (median diameter: $0.0236 \mu \mathrm{m})$, mixing ratio $(\mathrm{kg} / \mathrm{kg})$

BC2: black carbon hydrophilic dry (median diameter: $0.0236 \mu \mathrm{m})$, mixing ratio $(\mathrm{kg} / \mathrm{kg})$

OC1: particulate organic carbon hydrophobic dry (median diameter: $0.0424 \mu \mathrm{m})$, mixing ratio $(\mathrm{kg} / \mathrm{kg})$

OC2: particulate organic carbon hydrophilic dry (median diameter: $0.0424 \mu \mathrm{m})$, mixing ratio $(\mathrm{kg} / \mathrm{kg})$

SO4: sulfate dry (median diameter: $0.139 \mu \mathrm{m})$, mixing ratio $(\mathrm{kg} / \mathrm{kg})$

3. ngac.tCCz.aod_\$NM.grib2, where $\mathrm{NM}=11 \mathrm{p} 1 \mathrm{um,}$ $1 \mathrm{p} 63 \mathrm{um}, 340 \mathrm{~nm}, 440 \mathrm{~nm}, 550 \mathrm{~nm}, 660 \mathrm{~nm}, 860 \mathrm{~nm} \&$ $\mathrm{CC}=00,12$ : 
Total aerosol optical depth at specified wavelengths $(11.1,1.63,0.34,0.44,0.55,0.66$, and $0.86 \mu \mathrm{m})$. Please note: NGACv1 total aerosol optical depth is from dustonly. NGACv2 total aerosol optical depth is from multiple species including dust, sea salt, sulfate, black carbon, and particulate organic carbon.

New fields:

ngac.t00z.aod_550nm.grib2 file also contains aerosol optical depth at $550 \mathrm{~nm}$ from each species: dust, sea salt, sulfate, organic carbon, and black carbon. 
Competing interests. The authors declare that they have no conflict of interest.

Acknowledgements. The development of GBBEPx smoke emissions is funded by the Joint Center for Satellite Data Assimilation (JCSDA) Science Development and Implementation (JDSI). The NGACv2 tuning and evaluation work conducted by the UAlbany team (Cheng-Hsuan Lu, Sheng-Po Chen, and Shih-Wei Wei) has been partially supported by the NOAA Modeling, Analysis, Prediction, and Projections (MAPP) Climate Test Bed (CTB) (award number NA14OAR4310182) and NOAA Next Generation Global Prediction System (NGGPS) Research-toOperations Initiative (R2O) (award number NA15NWS4680008). The authors thank Richard Perez and Sergey Kivalov (University at Albany, State University of New York) for evaluating the impact of NGACv2 aerosol forecasts on the estimation of surface insolation. We also thank the Space Science and Engineering Center at University of Wisconsin-Madison for providing visible satellite images (http://www.ssec.wisc.edu/) and NASA Earth Observations for providing climatology data (https://earthobservatory.nasa.gov/GlobalMaps) in the surface insolation estimation experiment. The authors thank Li Pan and Hyun Kim for evaluating NGACv2 impact on CMAQ forecast. The authors appreciate the multi-model ensemble work done by the NRL for ICAP. The lead author Jun Wang gives special thanks to NCEP EMC management for project support and EMC colleagues for their scientific and technical inputs, including Shrinivas Moorthi, Yu-Tai Hou, Mark Iredell, and Boi Vuong. The lead author is grateful for the operational implementation support she got from NCEP NCO colleagues: Simon Hsiao, Xiaoxue Wang, Steven Earle, and Rebecca Cosgrove. The implementation evaluation by Craig Long, Peng Xian, and Jeff Reid is also greatly appreciated. Lastly, the authors would like to thank the two anonymous reviewers for their valuable suggestions and comments.

Edited by: Rolf Sander

Reviewed by: two anonymous referees

\section{References}

Albrecht, B.: Aerosols, Cloud Microphysics, and Fractional Cloudiness, Science, 245, 1227-1230, 1989.

Bhattacharjee, P. S., Wang, J., Lu, C.-H., and Tallapragada, V.: The implementation of NEMS GFS Aerosol Component (NGAC) Version 2.0 for global multispecies forecasting at NOAA/NCEP - Part 2: Evaluation of aerosol optical thickness, Geosci. Model Dev., 11, 2333-2351, https://doi.org/10.5194/gmd-112333-2018, 2018.

Bian, H., Chin, M., Kawa, S. R., Yu, H., Diehl, T., and Kucsera, T.: Multiscale Carbon Monoxide and aerosol correlations from satellite measurements and the GOCART model: implication for emissions and atmospheric evolution, J. Geophys. Res., 115, D07302, https://doi.org/10.1029/2009JD012781, 2010.

Bird, R. E. and Hulstrom, R. L.: A Simplified Clear Sky Model for Direct and Diffuse Insolation on Horizontal Surfaces, Solar Energy Research Institute, Golden, CO, TR-642-761, 33 pp., 1981.
Black, T., Juang, H. M. H., Yang, W. Y., and Iredell, M.: An ESMF framework for NCEP operational models, J3.1, in: 22nd Conference on Weather Analysis and Forecasting/18th Conference on Numerical Weather Prediction, Park City, UT, USA, 25-29 June 2007, American Meteorological Society, 2007.

Black, T., Juang, H. M. H., and Iredell, M.: The NOAA Environmental Modeling System at NCEP, 2A.6, Preprints, 23rd Conference on Weather Analysis and Forecasting/19th Conference on Numerical Weather Prediction, Omaga, NE, USA, 1-5 June 2009, American Meteorological Society, 2009.

Bond, T. C., Streets, D. G., Yarber, K. F., Nelson, S. M., Woo, J.-H., and Klimont, Z.: A technology-based global inventory of black and organic carbon emissions from combustion, J. Geophys. Res., 109, D14203, https://doi.org/10.1029/2003JD003697, 2004.

Chin, M., Rood, R. B., Lin, S.-J., Müller, J.-F., and Thompson, A. M.: Atmospheric sulfur cycle simulated in the global model GOCART: Model description and global properties, J. Geophys. Res., 105, 24671-24687, 2000a.

Chin, M., Savoie, D. L., Huebert, B. J., Bandy, A. R., Thornton, D. C., Bates, T. S., Quinn, P. K., Saltzman, E. S., and De Bruyn, W. J.: Atmospheric sulfur cycle in the global model GOCART: comparison with field observations and regional budgets, J. Geophys. Res., 105, 24689-24712, 2000b.

Chin, M., Ginoux, P., Kinne, S., Torres, O., Holben, B. N., Duncan, B. N., Martin, R. V., Logan, J. A., Higurashi, A., and Nakajima, T.: Tropospheric aerosol optical thickness from the GOCART model and comparisons with satellite and sunphotometer measurements, J. Atmos. Sci., 59, 461-483, 2002.

Chin, M., Ginoux, P., Lucchesi, R., Huebert, B., Weber, R., Anderson, T., Masonis, S., Blomquist, B., Bandy, A., and Thornton, D.: A global model forecast for the ACE-Asia field experiment, J. Geophys. Res., 108, 8654, https://doi.org/10.1029/2003JD003642, 2003.

Chin, M., Chu, A., Levy, R., Remer, L., Kaufman, Y., Holben, B., Eck, T., Ginoux, P., and Gao, Q.: Aerosol distributions in the northern hemisphere during ACE-Asia: results from global model, satellite observations and surface sun photometer measurements, J. Geophy. Res., 109, D23S90, https://doi.org/10.1029/2004JD004829, 2004.

Chin, M., Diehl, T., Ginoux, P., and Malm, W.: Intercontinental transport of pollution and dust aerosols: implications for regional air quality, Atmos. Chem. Phys., 7, 5501-5517, https://doi.org/10.5194/acp-7-5501-2007, 2007.

Chin, M., Diehl, T., Dubovik, O., Eck, T. F., Holben, B. N., Sinyuk, A., and Streets, D. G.: Light absorption by pollution, dust, and biomass burning aerosols: a global model study and evaluation with AERONET measurements, Ann. Geophys., 27, 3439-3464, https://doi.org/10.5194/angeo-27-3439-2009, 2009.

Colarco, P., da Silva, A., Chin, M., and Diehl, T.: Online simulations of global aerosol distributions in the NASA GEOS-4 model and comparisons to satellite and groundbased aerosol optical depth, J. Geophys. Res., 115, D14207, https://doi.org/10.1029/2009JD012820, 2010.

Colarco, P. R., Nowottnick, E. P., Randles, C. A., Yi, B., Yang, P., Kim, K.-M., Smith, J. A., and Bardeen, C. G.: Impact of radiatively interactive dust aerosols in the NASA GEOS-5 climate model, sensitivity to dust particle shape 
and refractive index, J. Geophys. Res.-Atmos., 119, 753-786, https://doi.org/10.1002/2013JD020046, 2014.

Cooke, W. F., Liousse, C., Cachier, H., and Feichter, J.: Contruction of a $1^{\circ} \times 1^{\circ}$ fossil fuel emission data set for carbonaceous aerosol and implementation and radiative impact in the ECHAM4 model, J. Geophys. Res., 104, 22137-22162, 1999.

Darmenov, A. and da Silva, A.: The Quick Fire Emissions Dataset (QFED) - Documentation of versions 2.1, 2.2 and 2.4, NASA Technical Report Series on Global Modeling and Data Assimilation, NASA/TM-2015-104606, Vol. 38, 211 pp., available at: http://citeseerx.ist.psu.edu/viewdoc/download?doi=10.1. 1.406.7724\&rep=rep1\&type=pdf (last access: 4 June 2018), 2015.

Diehl, T., Heil, A., Chin, M., Pan, X., Streets, D., Schultz, M., and Kinne, S.: Anthropogenic, biomass burning, and volcanic emissions of black carbon, organic carbon, and $\mathrm{SO}_{2}$ from 1980 to 2010 for hindcast model experiments, Atmos. Chem. Phys. Discuss., 12, 24895-24954, https://doi.org/10.5194/acpd-12-248952012, 2012.

Eyring, V., Kohler, H. W., van Aardenne, J., and Lauer, A.: Emissions from international shipping, 1. The last 50 years, J. Geophys., Res., 110, D17305, https://doi.org/10.1029/2004JD005619, 2005.

Fan, J., Rosenfeld, D., Yang, Y., Zhao, C., Leung, L. R., and Li, Z.: Substantial Contribution of Anthropogenic Air Pollution to Catastrophic Floods in Southwest China, Geophys. Res. Lett., 42, 6066-6075, https://doi.org/10.1002/2015GL064479, 2015.

Ginoux, P., Chin, M., Tegen, I., Prospero, J. M., Holben, B., Dubovik, O., and Lin, S.-J.: Sources and distributions of dust aerosols simulated with the GOCART model, J. Geophys. Res., 106, 20255-20273, https://doi.org/10.1029/2000JD000053, 2001.

Ginoux, P., Prospero, J. M., Torres, O., and Chin, M.: Longterm simulation of global dust distribution with the GOCART model: correlation with the North Atlantic Oscilation, Environ. Modell. Softw., 19, 113-128, https://doi.org/10.1016/S13648152(03)00114-2, 2004.

Gong, S. L.: A parameterization of sea-salt aerosol source function for sub and super-micron particles, Global Biogeochem. Cy., 17, 1097, https://doi.org/10.1029/2003GB002079, 2003.

Grell, G. and Baklanov, A.: Integrated modeling for forecasting weather and air quality: a call for fully coupled approaches, Atmos. Environ., 45, 6845-6851, 2011.

Guenther, A., Hewitt, C. N., Erickson, D., Fall, R., Geron, C., Graedel, T., Harley, P., Klinger, L., Lerdau, M., McKay, W. A., Pierce, T., Scholes, B., Steinbrecher, R., Tallamraju, R., Taylor, J., and Zimmerman, P.: A global model of natural volatile organic compound emissions, J. Geophys. Res., 100, 8873-8892, https://doi.org/10.1029/94JD02950, 1995.

Gueymard, C.: REST2: High-performance solar radiation model for cloudless-sky irradiance, illuminance, and photosynthetically active radiation - Validation with benchmark dataset, Sol. Energy, 82, 272-285, 2008.

Han, J. and Pan, H.-L.: Revision of convection and vertical diffusion schemes in the NCEP Global Forecast System, Weather Forecast., 26, 520-533, https://doi.org/10.1175/WAF-D-10-05038.1, 2011.

Han, J., Witek, M. L., Teixeira, J., Sun, R., Pan, H., Fletcher, J. K., and Bretherton, C. S.: Implementation in the NCEP
GFS of a hybrid eddy-diffusivity mass-flux (EDMF) boundary layer parameterization with dissipative heating and modified stable boundary layer mixing, Weather Forecast., 31, 341-352, https://doi.org/10.1175/WAF-D-15-0053.1, 2016.

Haywood, J. M. and Boucher, O.: Estimate of the direct and indirect radiative forcing due to tropospheric aerosols: A review, Rev. Geophys., 38, 513-543, https://doi.org/10.1029/1999RG000078, 2000.

Janssens-Maenhout, G.: EDGARv4.1 Emission Time Series, European Commission, Joint Research Centre (JRC) [Dataset] PID, available at: http://data.europa.eu/89h/ jrc-edgar-emissiontimeseriesv41 (last access: 12 June 2018), 2010.

Jickells, T. D., An, Z. S., Andersen, K. K., Baker, A. R., Bergametti, G., Brooks, N., Cao, J. J., Boyd, P. W., Duce, R. A., Hunter, K. A., Kawahata, H., Kubilay, N., laRoche, J., Liss, P. S., Mahowald, N., Prospero, J. M., Ridgwell, A. J., Tegen, I., and Torres, R.: Global Iron Connections between Desert Dust, Ocean Biogeochemistry, and Climate, Science 308, 67-71, 2005.

Kim, D. M., Chin, M., Bian, H., Tan, Q., Brown, M. E., Zheng, T., You, R., Diehl, T., Ginoux, P., and Kucsera, T.: The effect of the dynamic surface bareness on dust source function, emission and distribution, J. Geophys. Res.-Atmos., 118, 871-886, https://doi.org/10.1029/2012JD017907, 2013.

Koner, P. K. and Harris, A.: Sea surface temperature retrieval from MODIS radiances using truncated total least squares with multiple channels and parameters, Remote Sens., 8, 725, https://doi.org/10.3390/rs8090725, 2016.

Koner, P. K., Harris, A., and Maturi, E.: A physical deterministic inverse method for operational satellite remote sensing: an application for sea surface temperature retrievals, IEEE T. Geosci. Remote, 53, 5872-5888, 2015.

Koner, P. K., Harris, A., and Maturi, E.: Hybrid cloud and error masking to improve the quality of deterministic satellite sea surface temperature retrieval and data coverage, Remote Sens. Environ., 174, 266-278, 2016.

Lana, A., Bell, T. G., Simó, R., Vallina, S. M., Ballabrera-Poy, J., Kettle, A. J., Dachs, J., Bopp, L., Saltzman, E. S., Stefels, J., Johnson, J. E., and Liss, P. S.: An updated climatology of surface dimethlysulfide concentrations and emission fluxes in the global ocean, Global Biogeochem. Cy. 25, GB1004, https://doi.org/10.1029/2010GB003850, 2011.

Lee, P., McQueen, J., Stajner, I., Huang, J., Pan, L., Tong, D., Kim, H., Tang, Y., Kondragunta, S., Ruminski, M., Lu, S., Rogers, E., Saylor, R., Shafran, P., Huang, H., Gorline, J., Upadhayay, S., and Artz, R.: NAQFC developmental forecast guidance for fine particulate matter $\left(\mathrm{PM}_{2.5}\right)$, Weather Forecast., 32, 343-360, https://doi.org/10.1175/WAF-D-15-0163.1, 2017.

Liss, P. S. and Merlivat, L.: Air-Sea Gas Exchange Rates: Introduction and Synthesis, in: The Role of Air-Sea Exchange in Geochemical Cycling, edited by: Buat-Ménard, P., Springer, Dordrecht, NATO ASI Series (Series C: Mathematical and Physical Sciences), vol. 185, 1986.

Lohmann, U. and Feichter, J.: Global indirect aerosol effects: a review, Atmos. Chem. Phys., 5, 715-737, https://doi.org/10.5194/acp-5-715-2005, 2005.

Lu, C.-H., da Silva, A., Wang, J., Moorthi, S., Chin, M., Colarco, P., Tang, Y., Bhattacharjee, P. S., Chen, S.-P., Chuang, H.-Y., Juang, H.-M. H., McQueen, J., and Iredell, M.: The implementation of 
NEMS GFS Aerosol Component (NGAC) Version 1.0 for global dust forecasting at NOAA/NCEP, Geosci. Model Dev., 9, 19051919, https://doi.org/10.5194/gmd-9-1905-2016, 2016.

Lu, S., Huang, H.-C., Hou, Y.-T., Tang, Y., McQueen, J., da Silva, A., Chin, M., Joseph, E., and Stockwell, W.: Development of NCEP Global Aerosol Forecasting System: an overview and its application for improving weather and air quality forecasts, in: NATO Science for Peace and Security Series: Air Pollution Modelling and Its Application XX, Springer Publications, Dordrecht, the Netherlands, 451-454, https://doi.org/10.1007/978-90-4813812-8, 2010

Lundgren, K. B., Vogel, H., and Kottmeier, C.: Direct radiative effects of sea salt for the Mediterranean region under conditions of low to moderate wind speeds, J. Geophys. Res.-Atmos. 118, 1906-1923, 2013.

Lynch, P., Reid, J. S., Westphal, D. L., Zhang, J., Hogan, T. F., Hyer, E. J., Curtis, C. A., Hegg, D. A., Shi, Y., Campbell, J. R., Rubin, J. I., Sessions, W. R., Turk, F. J., and Walker, A. L.: An 11-year global gridded aerosol optical thickness reanalysis (v1.0) for atmospheric and climate sciences, Geosci. Model Dev., 9, 14891522, https://doi.org/10.5194/gmd-9-1489-2016, 2016.

Mahowald, N.: Aerosol Indirect Effect on Biogeochemical Cycles and Climate, Science, 334, 794-796, https://doi.org/10.1126/science.1207374, 2011.

Maria, S. F., Russell, L. M., Giles, M. K., and Myneni, S. C. B.: Organic aerosol growth mechanisms and their climate-forcing implications, Science, 306, 1921-1924, 2004.

Marticorena, B. and Bergametti, G.: Modeling the atmospheric dust cycle: 1. Design of a soil-derived dust emission scheme, J. Geophys. Res., 100, 16415-16430, https://doi.org/10.1029/95JD00690, 1995.

Mircea, M., Facchini, M. C., Decesari, S., Fuzzi, S., and Charlson, R. J.: The influence of the organic aerosol component on CCN supersaturation spectra for different aerosol types, Tellus B, 54, 74-81, 2002.

Monahan, E. C., Spiel, D. E., and Davidson, K. L.: A model of marine aerosol generation via whitecaps and wave disruption, in: Oceanic Whitecaps and their role in air-sea exchange processes, edited by: Mohahan, E. C. and MacNiocaill, G., D. Reidel, Norwell, Mass., 167-174, 1986.

Moorthi, S. and Suarez, M. J.: Relaxed Arakawa-Schubert: A parameterization of moist convection for general circulation models, Mon. Weather Rev., 120, 978-1002, 1992.

Moorthi, S. and Suarez, M. J.: Documentation of version 2 of Relaxed Arakawa-Schubert cumulus parameterization with convective downdrafts, NOAA Tech. Report NWS/NCEP 99-01, 44 pp., 1999.

Mulcahy, J. P., Walters, D. N., Bellouin, N., and Milton, S. F.: Impacts of increasing the aerosol complexity in the Met Office global numerical weather prediction model, Atmos. Chem. Phys., 14, 4749-4778, https://doi.org/10.5194/acp-144749-2014, 2014.

Perez, P., Ineichen, P., Seals, R., Michalsky, J., and Stewart, R.: Modeling daylight availability and irradiance components from direct and global irradiance, Sol. Energy, 44, 271-289, 1990.

Perez, R., Ineichen, P., Moore, K., Kmiecik, M., Chain, C., Georges, R., and Vignola, F.: A New Operational Satellite-to-Irradiance Model, Sol. Energy, 73, 307-317, 2002.
Perez, R., Schlemmer, J., Hemker, K., Kivalov, S., Kankiewicz, A., and Gueymard, G.: Satellite-to-Irradiance Modeling - A New Version of the SUNY Model, Proceedings of 42nd IEEE PV Specialists Conference, New Orleans, LA, 14-19 June 2015, IEEE, https://doi.org/10.1109/PVSC.2015.7356212, 2015.

Pincus, R., Barker, H. W., and Morcrette, J.-J.: A fast flexbile, approximate technique for computing radiatibe transfer in inhomogenoues cloud fields, J. Geophys. Res., 108, 4376, https://doi.org/10.1029/2002JD003322, 2003.

Ramanathan, V., Crutzen, P. J., Kiehl, J. T., and Rosenfeld, D.: Aerosols, climate, and the hydrological cycle, Science, 294, 2119-2124, 2001.

Reale, O., Lau, K. M., and da Silva, A.: Impacts of interactive aerosol on the African Easterly jet in the NASA GEOS5 global forecasting system, Weather Forecast., 26, 504-519, https://doi.org/10.1175/WAF-D-10-05025.1, 2011.

Rosenfeld, D.: Aerosol-Cloud Interactions Control of Earth Radiation and Latent Heat Release Budgets, Space Sci Rev., 125, 149157, https://doi.org/10.1007/s11214-006-9053-6, 2006

Rosenfeld, D., Woodley, W. L., Khain, A., Cotton, W. R., Carrió, G., Ginis, I., and Golden, J. H.: Aerosol effects on microstructure and intensity of the tropical cyclones, B. Am. Meteorol. Soc. 93, 987-1001, 2012.

Rosenfeld, D., Andreae, M. O., Asmi, A., Chin, M., de Leeuw, G., Donovan, D. P., Kahn, R., Kinne, S., Kivekäs, N., Kulmala, M., Lau, W., Schmidt, K. S., Suni, T., Wagner, T., Wild, M., and Quaas, J.: Global observations of aerosol-cloudprecipitation-climate interactionsm, Rev. Geophys., 52, 750808, https://doi.org/10.1002/2013RG000441, 2014.

Saide, P. E., Spak, S. N., Pierce, R. B., Otkin, J. A., Schaack, T. K., Heidinger, A. K., da Silva, A. M., Kacenelenbogen, M., Redemann, J., and Carmichael, G. R.: Central American biomass burning smoke can increase tornado severity in the U.S., Geophy. Res. Lett., 42, 956-965, 2015.

Sessions, W. R., Reid, J. S., Benedetti, A., Colarco, P. R., da Silva, A., Lu, S., Sekiyama, T., Tanaka, T. Y., Baldasano, J. M., Basart, S., Brooks, M. E., Eck, T. F., Iredell, M., Hansen, J. A., Jorba, O. C., Juang, H.-M. H., Lynch, P., Morcrette, J.-J., Moorthi, S., Mulcahy, J., Pradhan, Y., Razinger, M., Sampson, C. B., Wang, J., and Westphal, D. L.: Development towards a global operational aerosol consensus: basic climatological characteristics of the International Cooperative for Aerosol Prediction MultiModel Ensemble (ICAP-MME), Atmos. Chem. Phys., 15, 335362, https://doi.org/10.5194/acp-15-335-2015, 2015

Sokolik, I. N. and Toon, O. B.: Incorporation of mineralogical composition into models of the radiative properties of mineral aerosol from UV to IR wavelengths, J. Geophys. Res., 104, 9423-9444, https://doi.org/10.1029/1998JD200048, 1999.

Stevens, B. and Feingold, G.: Untangling aerosol effects on clouds and precipitation in a buffered system, Nature, 461, 607-613, 2009.

Streets, D. G., Yu, C., Wu, Y., Chin, M., Zhao, Z., Hayasaka, T., and Shi, G.: Aerosol trends over China, 1980-2000, Atmos. Res., 88, 174-182, https://doi.org/10.1016/j.atmosres.2007.10.016, 2008.

Streets, D. G., Yan, F., Chin, M., Diehl, T., Mahowald, N., Schultz, M., Wild, M., Wu, Y., and Yu, C.: Anthropogenic and natural contributions to regional trends in aerosol optical depth, 1980-2006, J. Geophys. Res., 114, D00D18, https://doi.org/10.1029/2008JD011624, 2009. 
Textor, C., Schulz, M., Guibert, S., Kinne, S., Balkanski, Y., Bauer, S., Berntsen, T., Berglen, T., Boucher, O., Chin, M., Dentener, F., Diehl, T., Easter, R., Feichter, H., Fillmore, D., Ghan, S., Ginoux, P., Gong, S., Grini, A., Hendricks, J., Horowitz, L., Huang, P., Isaksen, I., Iversen, I., Kloster, S., Koch, D., Kirkevåg, A., Kristjansson, J. E., Krol, M., Lauer, A., Lamarque, J. F., Liu, X., Montanaro, V., Myhre, G., Penner, J., Pitari, G., Reddy, S., Seland, Ø., Stier, P., Takemura, T., and Tie, X.: Analysis and quantification of the diversities of aerosol life cycles within AeroCom, Atmos. Chem. Phys., 6, 1777-1813, https://doi.org/10.5194/acp-6-17772006, 2006.

Tompkins, A. M., Cardinali, C., Morcrette, J. J., and Rodwell, M.: Influence of aerosol climatology on forecasts of the African Easterly jet, Geophy. Res. Lett., 32, L10801, https://doi.org/10.1029/2004GL022189, 2015

Twomey, S. A.: The influence of pollution on the shortwave albedo of clouds, J. Atmos. Sci., 34, 1149-1152, 1977.

Wang, Y.: Assessing the effects of anthropogenic aerosols on Pacific storm track using a multiscale climate model, P. Natl. Acad. Sci. USA, 111, 6894-6899, 2014.
Zhang, X., Kondragunta, S., Ram, J., Schmidt, C., and Huang, H.-C.: Near-real-time global biomass burning emissions product from geostationary satellite constellation, J. Geophys. Res., 117, D14201, https://doi.org/10.1029/2012JD017459, 2012.

Zhang, X., Kondragunta, S., da Silva, A., Lu, S., Ding, H., Li, F., and Zhu, Y.: The blended global biomass burning emissions product from MODIS and geostationary satellites (GBBEPx), http://www.ospo.noaa.gov/Products/land/ gbbepx/docs/GBBEPx_ATBD.pdf (last access: 1 June 2018), 2014.

Zhang, J., Reid, J. S., Christensen, M., and Benedetti, A.: An evaluation of the impact of aerosol particles on weather forecasts from a biomass burning aerosol event over the Midwestern United States: observational-based analysis of surface temperature, Atmos. Chem. Phys., 16, 6475-6494, https://doi.org/10.5194/acp16-6475-2016, 2016. 